\title{
The effect of titanium and silicon addition on phase equilibrium and mechanical properties of CoCrFeMnNi-based high entropy alloy
}

\author{
Syuki Yamanaka ${ }^{1} \oplus$, Ken-ichi Ikeda ${ }^{2}$, Seiji Miura ${ }^{2, a)} \odot$ \\ ${ }^{1}$ Division of Materials Science and Engineering, Graduate School of Engineering, Hokkaido University, Sapporo, Hokkaido 060-8628, Japan \\ ${ }^{2}$ Division of Materials Science and Engineering, Faculty of Engineering, Hokkaido University, Sapporo, Hokkaido 060-8628, Japan \\ a) Address all correspondence to this author. e-mail: miura@eng.hokudai.ac.jp \\ Received: 15 February 2021; accepted: 15 May 2021; published online: 7 June 2021
}

The effects of $\mathrm{Ti}$ and Si addition on the phase equilibrium and mechanical properties of the equiatomic $\mathrm{CoCrFeMnNi} \mathrm{high} \mathrm{entropy} \mathrm{alloy} \mathrm{(Cantor} \mathrm{alloy)} \mathrm{were} \mathrm{investigated.} \mathrm{The} \mathrm{phase} \mathrm{equilibrium} \mathrm{at} 1000^{\circ} \mathrm{C}$ was determined from the result of X-ray diffraction and electron probe micro-analysis. Ti addition stabilizes the $\sigma$ phase, A12 phase and C14-Laves phase, while Si addition stabilizes the A13 phase. The phase relationships were represented by projection onto ( $\mathrm{Co}, \mathrm{Fe}, \mathrm{Mn}, \mathrm{Ni})-\mathrm{Cr}-\mathrm{X}(\mathrm{Ti}$ or $\mathrm{Si})$ isothermal ternary cross-section at $1000^{\circ} \mathrm{C}$ in $\mathrm{Co}-\mathrm{Cr}-\mathrm{Fe}-\mathrm{Mn}-\mathrm{Ni}-\mathrm{X}$ senary system. Tensile tests were conducted on Cantorbased fcc single solid solution alloys with Ti or Si dissolution at room temperature. The $0.2 \%$ yield strength and ultimate tensile strength increased with either element addition. The Ti-added alloy showed higher strength than the Si-added alloy. The difference in ductility in the alloys is related to their strain hardening behavior in the higher strain range.

\section{Introduction}

Recently, high entropy alloys, which are composed of multiple principal elements, have been attracting attention as structural materials. The concept of a high entropy alloy was first proposed by Yeh et al.[1], and Cantor et al. reported a face-centered cubic (fcc) single solid solution alloy composed of equiatomic Co, Cr, $\mathrm{Fe}, \mathrm{Mn}$ and Ni (well-known as Cantor alloy) [2]. These multicomponent alloys with near equiatomic composition show excellent properties such as high strength and high ductility [3-7].

For further improvement of their properties, introduction of some second phases has been attempted by replacing one or more of the constituent elements or adding more elements [8-11]. Cantor alloy is known for its good ductility at cryogenic temperature and room temperature $[3,12]$. Hence, this alloy has the potential to achieve a better strength-ductility balance by adjusting the alloy composition and introducing a second phase. Although many studies on the development of Cantorbased multi-phase alloys have been conducted, few studies have focused on the phase equilibrium. Although various researchers reported that the addition of an extra element introduces second phases into Cantor alloy, few studies have focused on the phase equilibrium in well-homogenized alloys [13-19]. However, for Cantor-based multi-phase alloy development, information on the phase constituents and chemical composition in a homogeneous state is crucial. Thus, more detailed studies are required to choose effective additive elements and determine alloy compositions. This would also be the basis for the development of a CALPHAD-type database for phase diagram calculations.

Also, graphical expression methods, such as a ternary phase diagram, to represent an overview of the phase equilibrium in Cantor-based multi-phase alloys are also important. They make it easy to adjust the amount of each constituent element for second phase selection. However, it is difficult to represent the phase composition of a multi-component alloy in a single diagram, because no polyhedron can represent five or more independent components as apexes in three-dimensional space. Furthermore, three-dimensional expressions, i.e., a quaternary expression, are not easily understood. An isothermal section diagram, which is a triangle cut out from higher-order phase diagrams at a certain temperature, has been generally used in ternary phase diagrams. In this study, the authors propose an application of the two-dimensional expression method to show the phase equilibrium in senary 
systems near Cantor alloy, by projecting the composition of each constituent phase. It enables us to easily understand changes in phase relationships with a 6 th element addition.

Generally, ductility and strength have a "trade-off" relationship. In order to overcome such a relationship in solid solution alloys, other strengthening methods, such as precipitation strengthening, have been applied. However, when using a brittle intermetallic compound as a strengthening phase, the matrix should have sufficient ductility, while it is unclear how additive elements dissolved into Cantor-based solid solutions affect their ductility. In this study, the mechanical properties of Cantorbased single fcc alloys with dissolution of a 6 th element were also investigated.

The authors selected $\mathrm{Ti}$ and $\mathrm{Si}$ as the 6 th additive elements because these elements tend to form some compounds, such as $\mathrm{CoTi}, \mathrm{Cr}_{3} \mathrm{Si}, \mathrm{Fe}_{2} \mathrm{Ti}, \mathrm{Mn}_{5} \mathrm{Si}_{3}$ and $\mathrm{Ni}_{3} \mathrm{Ti}$, with each constituent element of the alloy, Co, Cr, Fe, Mn and $\mathrm{Ni}[20,21]$. Thus, it is expected that $\mathrm{Ti}$ or $\mathrm{Si}$ addition can introduce a second phase into the Cantor alloy. To the best of our knowledge, there are only two reports related to the addition of Ti to Cantor alloy, and no reports on the effect of Si addition were found. Qin et al. reported that Ti addition introduces Laves phases in as-cast $(\mathrm{CoCrFeMnNi})_{100-x} \mathrm{Ti}_{x}$ alloys ( $x=6 \sim 12)$ [13]. Shahmir et al. reported two nano-precipitates with bcc structure and $\sigma$ structure in $(\mathrm{CoCrFeMnNi})_{98} \mathrm{Ti}_{2}$ alloy and conducted tensile tests after high-pressure torsion and annealing at $600-800{ }^{\circ} \mathrm{C}$ for $60 \mathrm{~min}$ [14]. Their studies showed that $\mathrm{Ti}$ dissolution and introduction of these second phases can improve the strength of Cantor alloy.

Our research goal is the development of a series of Cantorbased multi-phase alloys with a good balance of high strength and high ductility. In this study, the authors proposed the use of a (Co, Fe, Mn, Ni)-Cr-X (Ti or Si) cross-section of the senary systems as the two-dimensional expression method for the phase diagram for the Cantor alloy, and investigated the effect of $\mathrm{Ti}$ and $\mathrm{Si}$ addition on the phase equilibrium and mechanical properties in Cantor-based fcc solid solution with various alloys, as the basis for a further investigation on precipitation strengthening by $\mathrm{Ti}$ or Si-based precipitates. Each constituent phase was characterized by X-ray diffraction (XRD) and an electron probe micro-analyzer (EPMA). Tensile tests were conducted on some of the recrystallized specimens of fcc single-phase alloys at room temperature.

\section{On the expression of phase relationship on two-dimensional cross-section in senary phase diagram}

Phase diagrams must have the following information: (1) single-phase area (2) chemical composition of alloys and phases. (3) relationship between constituent phases. This information enables us to understand the effect of constituent elements on
TABLE 1: The fcc solid solution region formed by the constituent elements of CoCrFeMnNi high entropy alloy in binary system [20].

\begin{tabular}{|c|c|c|c|c|c|c|}
\hline \multirow{2}{*}{\multicolumn{2}{|c|}{$\begin{array}{c}\text { Maximum } \\
\text { solubility } \\
\text { (at.\%) }\end{array}$}} & \multicolumn{5}{|c|}{ Solvent (fcc solid solution) } \\
\hline & & $\mathrm{Cr}$ & $\mathrm{Fe}$ & $\mathrm{Mn}$ & $\mathrm{Co}$ & $\mathrm{Ni}$ \\
\hline \multirow{5}{*}{ 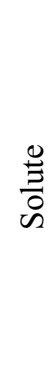 } & $\mathrm{Cr}$ & & $12^{\mathrm{a}}$ & $7^{\mathrm{a}}$ & $43^{\mathrm{a}}$ & 50 \\
\hline & $\mathrm{Fe}$ & $-^{\mathrm{a}}$ & & 100 & 100 & 100 \\
\hline & $\mathrm{Mn}$ & $-^{\mathrm{a}}$ & 100 & & $59^{\mathrm{a}}$ & 100 \\
\hline & $\mathrm{Co}$ & $-\mathrm{a}$ & 100 & $5^{\mathrm{a}}$ & & 100 \\
\hline & $\mathrm{Ni}$ & $-{ }^{a}$ & 100 & 100 & 100 & \\
\hline
\end{tabular}

The value means the maximum solubility when the second column element dissolves in the corresponding row element. The value "100" means the formation of continuous solid solution.

${ }^{\mathrm{a}}$ Formation of $\sigma$ phase.

phase stability and estimate the volume fractions of constituent phases. For a phase diagram expression of a multi-component system that satisfies these requirements, a cross-section must be selected. The $\mathrm{CaO}-\mathrm{Al}_{2} \mathrm{O}_{3}-\mathrm{SiO}_{2}$ pseudo-ternary phase diagram is a good example [22]. This system is composed of four elements, $\mathrm{Ca}, \mathrm{Al}, \mathrm{Si}$ and $\mathrm{O}$. However, the overall compositional information, such as Al-Si equilibrium, may not be necessary to focus on a certain phase equilibrium between $\mathrm{CaO}, \mathrm{Al}_{2} \mathrm{O}_{3}$ and $\mathrm{SiO}_{2}$. By considering a certain compound as an apex, it is possible to represent the quaternary phase equilibrium in the form of a ternary phase diagram section.

The authors propose a simple expression method that makes it easier to understand phase relationships in a multicomponent system: the projection of each constituent phase composition obtained from several alloys onto a single crosssection in the form of a ternary phase diagram. As a suitable cross-section, it must include a line from the CoCrFeMnNi equiatomic composition to pure $\mathrm{X}$ ( $\mathrm{Ti}$ or $\mathrm{Si}$ ). From this point of view, pseudo-binary phase diagrams seem to be among the candidates. However, it was found in the present investigation that the $\sigma$ single-phase field (Pearson symbol: tP30) is not on the line between the Cantor composition and pure X. The $\sigma$ phase stability is closely related to the interaction among constituent elements of the Cantor alloy. Table 1 shows the fcc region in binary systems of each constituent element in Cantor alloys, such as $\mathrm{Co}-\mathrm{Cr}, \mathrm{Co}-\mathrm{Fe}$ and Co-Mn [20]. Pure- $\mathrm{Co}$, $\mathrm{Fe}, \mathrm{Mn}$ and Ni have fcc structure as one of their stable phases, while $\mathrm{Cr}$ has only the body-centered cubic structure. As shown in Table I, most of the fcc elements form continuous solid 
solutions with other fcc elements. However, instead of forming an fcc continuous solid solution, $\mathrm{Cr}$ tends to form $\sigma$ phases with most of these fcc elements. Hence, it is not appropriate to treat $\mathrm{Cr}$ as an element having a similar character to the others. In addition, some previous studies reported $\mathrm{Cr}$-rich $\sigma$ phases in Cantor alloy annealed at a medium temperature [23-25]. Otto et al. reported that a Cr-rich $\sigma$ phase appears in equiatomic Cantor alloy annealed for up to 500 days at $700{ }^{\circ} \mathrm{C}$ [23]. Klimova et al. confirmed fcc- $\sigma$-bcc three-phase equilibrium in equiatomic Cantor alloy annealed for $2 \mathrm{~h}$ at $600^{\circ} \mathrm{C}$, while with increasing annealing time, the volume fraction of the bcc phase decreased and that of the $\sigma$ phase increased [24]. Laplanche et al. reported that the 20at.\%Co- 26at.\%Cr20at.\%Fe- 20 at.\%Mn- 14 at.\%Ni alloy had an fcc- $\sigma$ two-phase microstructure after annealing for $1000 \mathrm{~h}$ at $1000{ }^{\circ} \mathrm{C}$ [25]. These results imply that the stability of $\sigma$ phases appearing in the Cr-rich area needs to be taken into account for the design of Cantor-based alloys. Therefore, Cr was selected as one of three apexes in the pseudo-ternary phase diagram because it is a $\sigma$ former element, and the fcc elements $\mathrm{Co}, \mathrm{Fe}, \mathrm{Mn}$ and $\mathrm{Ni}$ were represented as another apex. To place the Cantor alloy composition on the ( $\mathrm{Co}, \mathrm{Fe}, \mathrm{Mn}, \mathrm{Ni})-\mathrm{Cr}$ axis, the ratio of ( $\mathrm{Co}, \mathrm{Fe}, \mathrm{Mn}, \mathrm{Ni})$ must be equal to each other throughout this diagram. Then, the phase composition of each alloy was projected into the equiatomic $(\mathrm{Co}, \mathrm{Fe}, \mathrm{Mn}, \mathrm{Ni})-\mathrm{Cr}-\mathrm{X}$ (= Ti or $\mathrm{Si})$ pseudo-ternary diagram as shown in Online Resource 1.

Table 2 lists the nominal compositions of each alloy prepared in this study. Three series of alloy compositions were selected primarily to establish the phase diagrams (See Online Resource 1). Here the capital letter $\mathrm{T}$ or $\mathrm{S}$ placed at the end of the alloy number means Ti-added alloy or Si-added alloy, respectively. In series No.1 alloys, the $\mathrm{Cr}$ content was systematically varied along the (Co, $\mathrm{Fe}, \mathrm{Mn}, \mathrm{Ni})-\mathrm{Cr}$ axis. In series No.2 alloys, additive elements $\mathrm{X}$ ( $\mathrm{Ti}$ or $\mathrm{Si}$ ) and $\mathrm{Cr}$ were added to the equiatomic CoFeMnNi alloy. In series No.3 alloys, $\mathrm{X}$ and $\mathrm{Cr}$ were added to Cantor alloy. In all these alloys, the ratios of Co,
TABLE 2: The nominal composition produced in this study. Series No. 1-No. 3 alloys were used to investigate phase equilibrium.

\begin{tabular}{|c|c|c|c|c|c|c|c|c|}
\hline Series & No & Co & $\mathrm{Cr}$ & $\mathrm{Fe}$ & $\mathrm{Mn}$ & $\mathrm{Ni}$ & $\mathrm{Ti}$ & $\overline{\mathrm{Si}}$ \\
\hline \multirow[t]{7}{*}{ No. 1} & $\# 0$ & 20 & 20 & 20 & 20 & 20 & - & - \\
\hline & $\# 1$ & 25 & - & 25 & 25 & 25 & - & - \\
\hline & $\# 2$ & 19 & 24 & 19 & 19 & 19 & - & - \\
\hline & $\# 3$ & 18 & 28 & 18 & 18 & 18 & - & - \\
\hline & $\# 4$ & 17 & 32 & 17 & 17 & 17 & - & - \\
\hline & $\# 5$ & 16 & 36 & 16 & 16 & 16 & - & - \\
\hline & $\# 6$ & 14 & 44 & 14 & 14 & 14 & - & - \\
\hline \multirow[t]{4}{*}{ No. 2} & \#7T & 22.5 & - & 22.5 & 22.5 & 22.5 & 10 & - \\
\hline & $\# 8 \mathrm{~T}$ & 21.25 & - & 21.25 & 21.25 & 21.25 & 15 & - \\
\hline & \#9T & 20 & - & 20 & 20 & 20 & 20 & - \\
\hline & $\# 10 \mathrm{~T}$ & 20 & 5 & 20 & 20 & 20 & 15 & - \\
\hline \multirow[t]{4}{*}{ No. 3} & $\# 11 \mathrm{~T}$ & 19.2 & 19.2 & 19.2 & 19.2 & 19.2 & 4 & - \\
\hline & $\# 12 \mathrm{~T}$ & 19 & 19 & 19 & 19 & 19 & 5 & - \\
\hline & $\# 13 \mathrm{~T}$ & 18 & 18 & 18 & 18 & 18 & 10 & - \\
\hline & $\# 14 \mathrm{~T}$ & 17 & 17 & 17 & 17 & 17 & 15 & - \\
\hline \multirow[t]{4}{*}{ No. 2} & $\# 15 S$ & 22.5 & - & 22.5 & 22.5 & 22.5 & - & 10 \\
\hline & $\# 16 \mathrm{~S}$ & 21.25 & - & 21.25 & 21.25 & 21.25 & - & 15 \\
\hline & $\# 175$ & 20 & - & 20 & 20 & 20 & - & 20 \\
\hline & $\# 18 \mathrm{~S}$ & 20 & 5 & 20 & 20 & 20 & - & 15 \\
\hline \multirow[t]{6}{*}{ No. 3} & $\# 19 S$ & 19 & 19 & 19 & 19 & 19 & - & 5 \\
\hline & $\# 20 \mathrm{~S}$ & 18.6 & 18.6 & 18.6 & 18.6 & 18.6 & - & 7 \\
\hline & $\# 21 \mathrm{~S}$ & 18 & 18 & 18 & 18 & 18 & - & 10 \\
\hline & $\# 22 \mathrm{~S}$ & 17 & 17 & 17 & 17 & 17 & - & 15 \\
\hline & $\# 23 \mathrm{~S}$ & 15 & 35 & 15 & 15 & 15 & - & 5 \\
\hline & $\# 24 S$ & 15 & 30 & 15 & 15 & 15 & - & 10 \\
\hline \multirow[t]{3}{*}{ No. 4} & $\# 25$ & 20 & 20 & 20 & 20 & 20 & - & - \\
\hline & $\# 26 \mathrm{~T}$ & 19.6 & 19.6 & 19.6 & 19.6 & 19.6 & 2 & - \\
\hline & $\# 275$ & 19.2 & 19.2 & 19.2 & 19.2 & 19.2 & - & 4 \\
\hline \multirow[t]{2}{*}{ No. 5} & $\# 28 \mathrm{~T}$ & 17.0 & 32.8 & 18.7 & 16.3 & 10.0 & 5.2 & - \\
\hline & \#29T & 18.9 & 24.1 & 18.8 & 17.3 & 11.6 & 9.3 & - \\
\hline
\end{tabular}

Series No. 4 alloys were used for the tensile tests. Series No. 5 alloys were used to reveal the constituent phases in the alloy \#12T. 
$\mathrm{Fe}, \mathrm{Mn}$ and $\mathrm{Ni}$ were kept equiatomic in nominal composition. Series No.4 alloys were prepared for tensile specimens. Series No.5 alloys were also prepared to confirm the crystal structure of constituent phases in the alloy \#12 T.

\section{Results and discussion}

\section{The phase equilibrium in the (Co, $\mathrm{Fe}, \mathrm{Mn}, \mathrm{Ni})-\mathrm{Cr}$ system (Series No. 1)}

Figure 1 shows backscattered electron images and XRD profiles of typical series No.1 alloys annealed for $168 \mathrm{~h}$ at $1000^{\circ} \mathrm{C}$. (See Online Resource 2 for details of the phase composition of these alloys). From XRD analysis and microstructure observation, it was confirmed that alloys \#0 and \#1 are fcc single solid solution alloys. This result agrees with the results in previous studies $[2-4,26]$. As shown in Fig. 1a and d, it was confirmed that alloy $\# 2$ is a single fcc solid solution alloy. In higher $\mathrm{Cr}$ alloys (alloys \#3, \#4, \#5, and \#6), second phases were observed. From XRD analysis and microstructure observation (Fig. 1c, d), it was found that alloy \#5 has a two-phase microstructure consisting
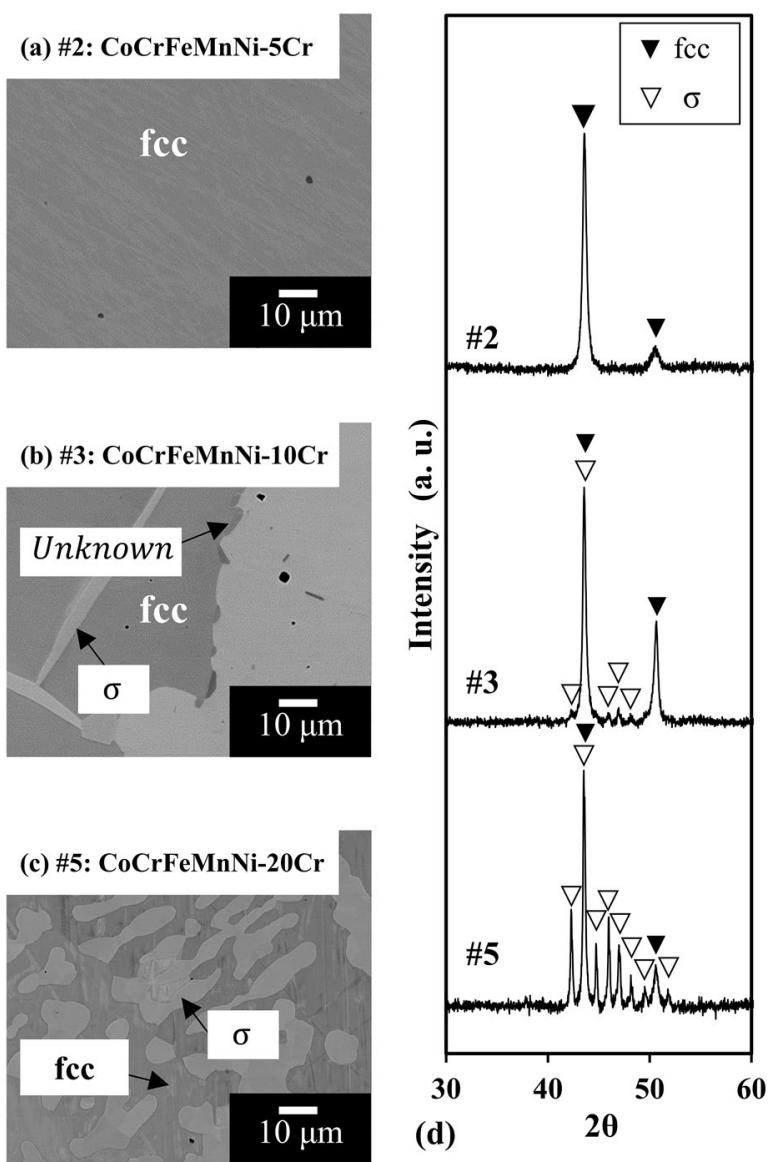

Figure 1: The backscattered electron images of (a) \#2, (b) \#3 and (c) \#5 alloys annealed for $168 \mathrm{~h}$ at $1000^{\circ} \mathrm{C}$, respectively. XRD profiles of these alloys are shown in (d). of fcc phase and $\sigma$ phase. This result is also found in alloys \#4 and \#6. Figure 1 (b) shows there are two minor phases observed in an fcc matrix in alloy \#3. The XRD profile (Fig. 1d) indicates that this alloy is composed of major fcc and minor $\sigma$ phases. According to the EPMA analysis, the plate-like precipitates are $\sigma$ phase having almost the same composition as that in \#4, and small particles are at fcc-fcc grain boundaries. The crystal structure of the latter has not been determined yet and it is called the unknown phase temporarily in the present study. Although Cantor alloy is taken as an equiatomic fcc single solid solution alloy, several studies reported the existence of some second phases other than $\sigma$ phase as discussed in the previous section. For example, Otto et al. reported that $\mathrm{Ni}$ and $\mathrm{Mn}$-rich $\mathrm{L} 1_{0}$ phase, Cr-rich bcc phase, and Fe and Co-rich B2 phase appeared in the fcc matrix in Cantor alloy annealed at $500^{\circ} \mathrm{C}$ [23]. Klimova et al. reported bcc particles in Cantor alloy annealed at $600{ }^{\circ} \mathrm{C}$ [24]. Further experimental studies are needed to extend the knowledge on the phase equilibrium around the composition of Cantor alloy.

\section{Effect of Ti addition on the phase equilibrium in the (Co, Fe, Mn, Ni)-Cr system (Series No. 2 and No.}

\section{3)}

Figure 2 shows backscattered electron images and XRD profiles of some samples of typical Ti-added alloys. (See Online Resource 3 for the details of the phase composition of these alloys.) In series No.2 alloys \#7 T, \#8 T, and \#9 T, the C14-Laves phase (Pearson symbol: hP12) was confirmed, together with the fcc phase (Fig. 2a, g). It is also confirmed that alloy \#10 T has both fcc and C14-Laves phases, which shows that the small $\mathrm{Cr}$ addition does not change the constituent phases.

Among series No. 3 alloys with Ti, only the alloy \#11 T is a single fcc solid solution alloy (Fig. 2b, g), while the other series No. 3 alloys (\#12 T-\#14 T) have various second phases. Ti solubility in the equiatomic CoCrFeMnNi alloy is about 4 at.\% at $1000{ }^{\circ} \mathrm{C}$. It is confirmed that there are Cr-rich phase and Crmedium phase in a Cr-poor fcc matrix in alloy \#12 T (Fig. 2c, $\mathrm{d}$ show its Cr mapping). XRD results (Fig. 2g) show that these minor phases have either the $\sigma$ structure or A12 structure (Pearson symbol: cI58). In order to obtain information on the crystal structure and composition of these phases in alloy \#12 T, alloys \#28 T and \#29 T were prepared and examined. (See Online Resource 4 for details of the microstructure, XRD profiles and phase composition.) The XRD results indicate that alloy \#28 T has the $\sigma$ phase and alloy \#29 T has the A12 phase. Thus, the crystal structures of the $\mathrm{Cr}$-rich phase and $\mathrm{Cr}$-medium phase in alloy \#12 $\mathrm{T}$ are the $\sigma$ structure and $\mathrm{A} 12$ structure, respectively. With increasing Ti content, the $\sigma$ phase disappears and a small amount of $\mathrm{C} 14$ phase appears in the fcc-A12 two-phase structure in alloy \#13 T (Fig. 2e). Then, with further increase of 
(a) \#8T: CoFeMnNi-15Ti

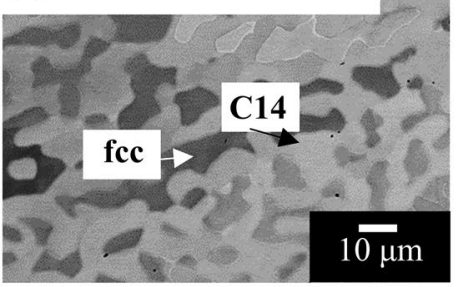

(c) \#12T: CoCrFeMnNi-5Ti

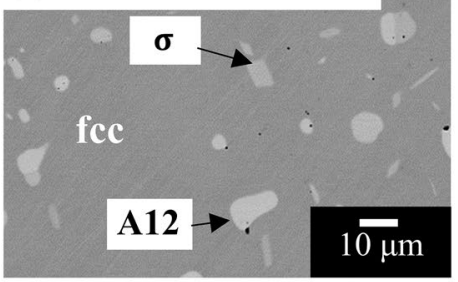

(e) \#13T: CoCrFeMnNi-10Ti

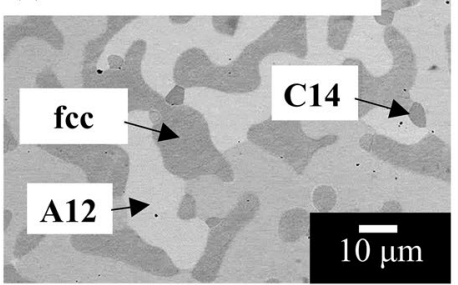

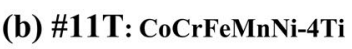

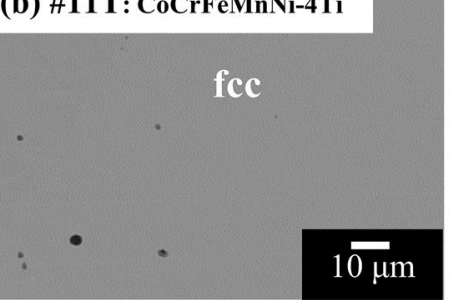

(d) \#12T - Cr map

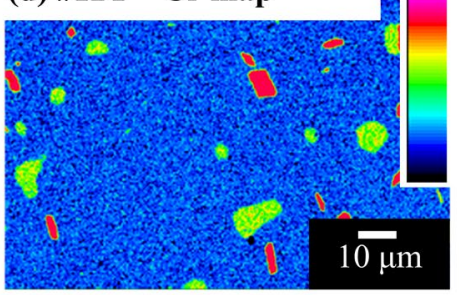

(f) \#14T: CoCrFeMnNi-15Ti

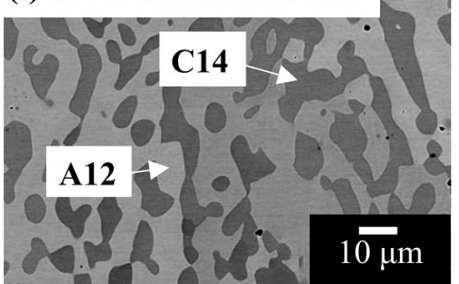

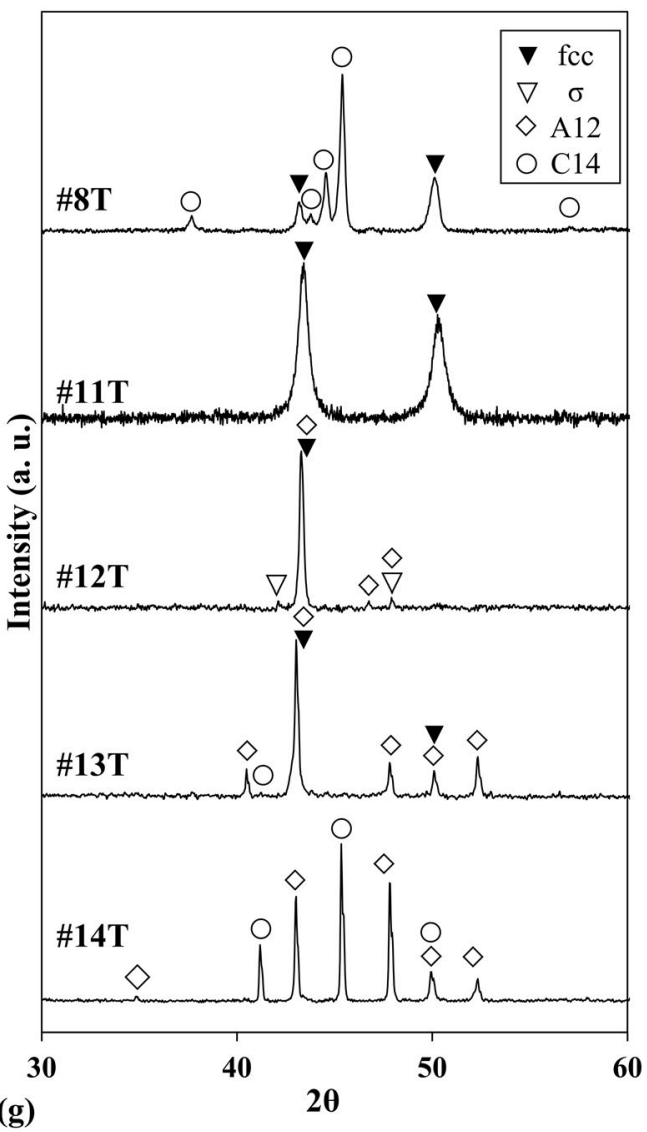

(g)
20

Figure 2: The backscattered electron images of alloys (a)\#8T, (b)\#11T, (c)\#12T, (e)\#13T, and (f) \#14T, annealed for $168 \mathrm{~h}$ at $1000{ }^{\circ} \mathrm{C}$, respectively. XRD profiles of these alloys are shown in (g). (d) shows WDS mapping of $\mathrm{Cr}$ in the same region as (c) analyzed by EPMA. The color follows the color bar on the right side of this figure where higher colors represent $\mathrm{Cr}$ content higher in the analytical range.

Ti, the fcc phase disappears in alloy \#14 T, while the A12 phase is confirmed as a major phase with a higher volume fraction of C14 phase than in alloy \#13 T (Fig. 2f).

\section{Effect of Si addition on the phase equilibrium in the (Co, Fe, Mn, Ni)-Cr system (Series No. 2 and No.}

\section{3)}

Figure 3 shows backscattered electron images and XRD profiles of some samples of typical Si-added alloys annealed for $168 \mathrm{~h}$ at $1000{ }^{\circ} \mathrm{C}$. (See Online Resource 5 for details of the phase composition of these alloys.) In series No.2 alloys, fcc-C14-Laves two-phase equilibrium was confirmed in low Si alloy \#15S (Fig. 3a). Then, the A13 phase (Pearson symbol: cP20) appears as a third phase in medium Si alloy \#16S (Fig. 3b). Finally, the high Si alloy \#17S has small particles of $\mathrm{G}$ phase (Pearson symbol: cF116) in an A13 matrix (Fig. 3c). On the other hand, it was found that the C14 phase disappeared in alloy \#18S (Fig. 3d). Cr is equally distributed to the fcc and A13 phases. Therefore, it can be concluded that the addition of 5 at.\% of Cr to alloy \#16S results in stabilization of both the fcc and A13 phases in alloy \#18S.

Among the series No.3 alloys, alloy \#20S was confirmed to be fcc single solid solution alloys, while alloy \#22S was fcc-A13 two-phase alloy from the results of XRD and microstructure observation (Fig. 3e, f, and i). Similarly, alloys \#19S and \#21S were confirmed to be fcc single-phase and fcc-A13 two-phase alloys, respectively. These results suggest that $\mathrm{Si}$ solubility in Cantor alloy is about 7 at. $\%$ at $1000{ }^{\circ} \mathrm{C}$, and the $\mathrm{A} 13$ phase has a long solubility lobe along a line of about 15 at.\%Si from the (Co, Fe, Ni, Mn)-Si axis to a Cr content as high as 30 at.\%.

To confirm the effect of $\mathrm{Cr}$ content on the phase equilibrium in the high Cr region, alloys \#23S and \#24S were prepared and examined. In both cases, it was confirmed that the $\sigma$ phase appears. Therefore, it was found that $\mathrm{Cr}$ content stabilizes the $\sigma$ phase in low Si regions. These phases found in alloy \#24S (Fig. 3g) were confirmed by Fe mapping (Fig. 3h). The Fe-rich phase, Fe-medium phase, and Fe-poor phase correspond to fcc phase, $\sigma$ phase and A13 phase, respectively. 
(a) \#15S: CoFeMnNi-10Si

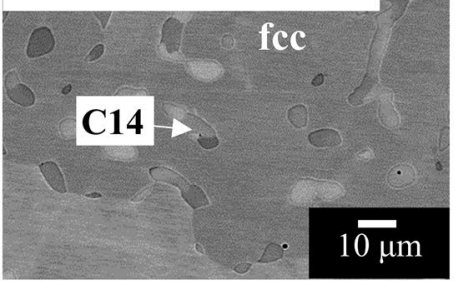

(c) \#17S: CoFeMnNi-20Si

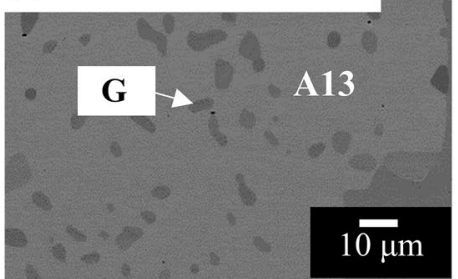

(e) \#20S: CoCrFeMnNi-7Si

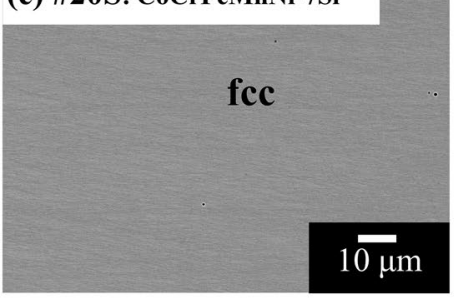

(g) \#24S: CoCrFeMnNi-10Si-15Cr

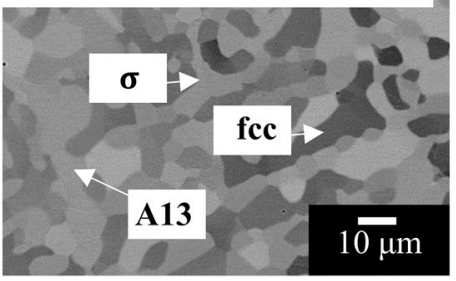

(b) \#16S: CoFeMnNi-15Si

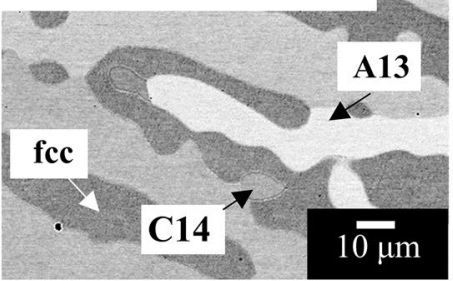

(d) \#18S: CoFeMnNi-15Si-5Cr

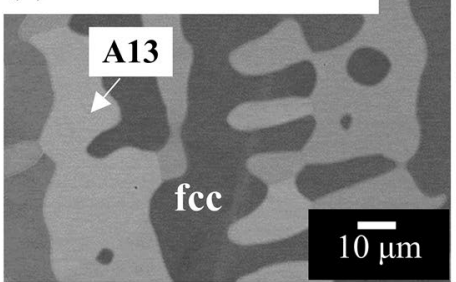

(f) \#22S: CoCrFeMnNi-15Si
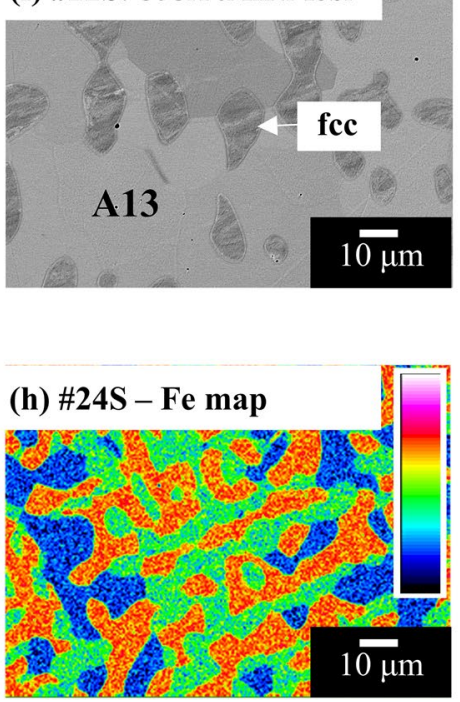

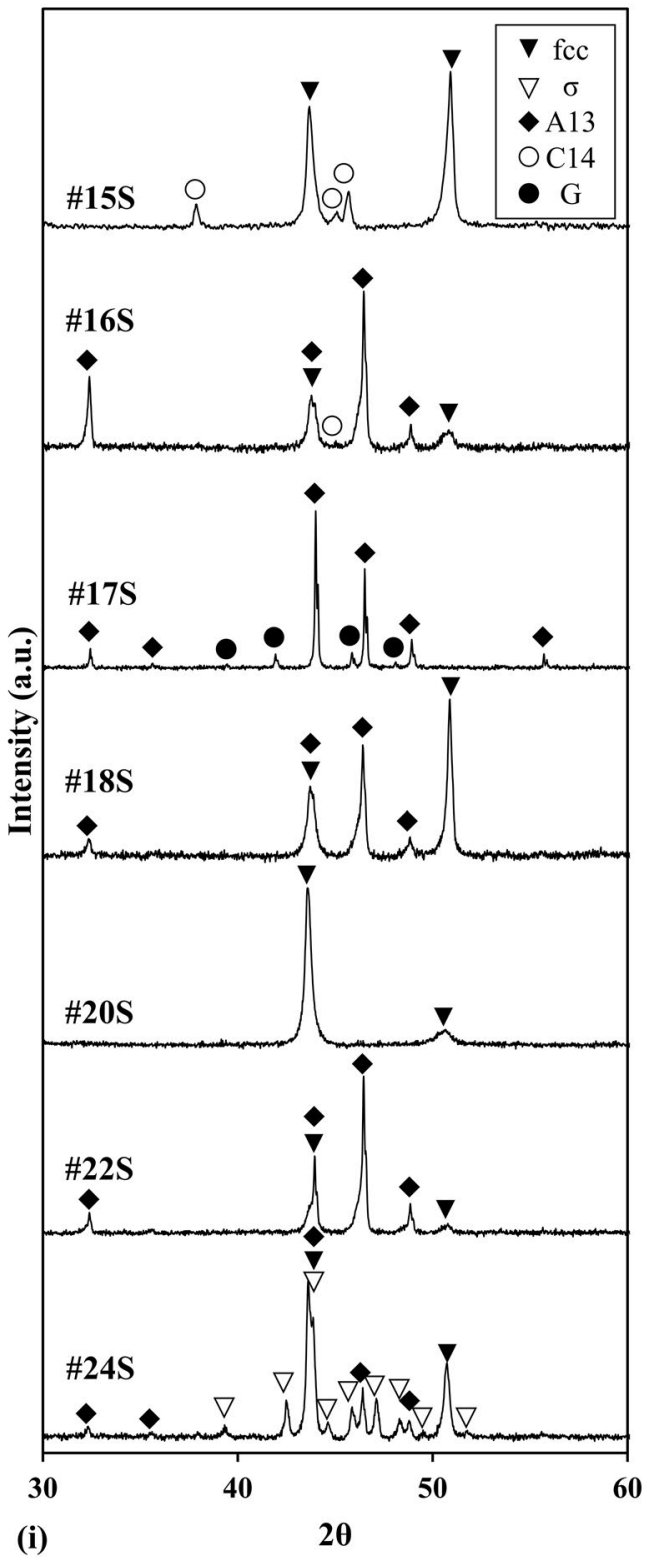

(i)

Figure 3: The backscattered electron images of alloys (a) \#15S, (b) \#16S, (c)\#17S, (d)\#18S, (e)\#20S, (f)\#22S, and (g) \#24S, annealed for $168 \mathrm{~h}$ at $1000^{\circ} \mathrm{C}$, respectively. XRD profiles of these alloys are shown in (i). (h) shows WDS mapping of Fe in the same region as $(\mathrm{g})$ analyzed by EPMA. The color follows the color bar on the right side of this figure where higher colors represent Fe content higher in the analytical range.

\section{Two-dimensional expression of phase relationship in $\mathrm{Co}-\mathrm{Cr}-\mathrm{Fe}-\mathrm{Mn}-\mathrm{Ni}-\mathrm{Ti}$ or Si senary system}

The phase relationship of the senary phase diagram of $\mathrm{Cr}$ and an additive element ( $\mathrm{Ti}$ or $\mathrm{Si}$ ) at $1000{ }^{\circ} \mathrm{C}$ projected on a (Co, Fe, Mn, Ni)- equiatomic section is summarized in Fig. 4. Each phase composition found in the alloys investigated is projected on these diagrams, except for the unknown phase in alloy \#4 and C14-Laves phase in Si-added alloys because the compositions of theses phase are far from the (Co, Fe, $\mathrm{Mn}, \mathrm{Ni}$ )-Cr-X section. (See Online Resource 2, 3, and 5 for information on composition).
Figure 4 clearly shows that co-doping of $\mathrm{Cr}$ and Ti to Cantor alloy strongly stabilizes the $\sigma$ phase. Ti addition also stabilizes the A12 and C14-Laves phases, while Si addition stabilizes the A13 phase strongly, and $\sigma$ phase stability is also rather enhanced by $\mathrm{Si}$ in the high $\mathrm{Cr}$ region (Fig. $4 \mathrm{~b}$ ).

These diagrams cannot exactly express the phase relationship between each phase on the quinary edges. For example, the relationship between the C14-Laves phase and A13 phase in alloys \#15S and \#16S, and between the $\sigma$ phase and unknown phase in alloy \#3. However, they tell us which phase can be introduced to the Cantor-based fcc matrix. These diagrams can 


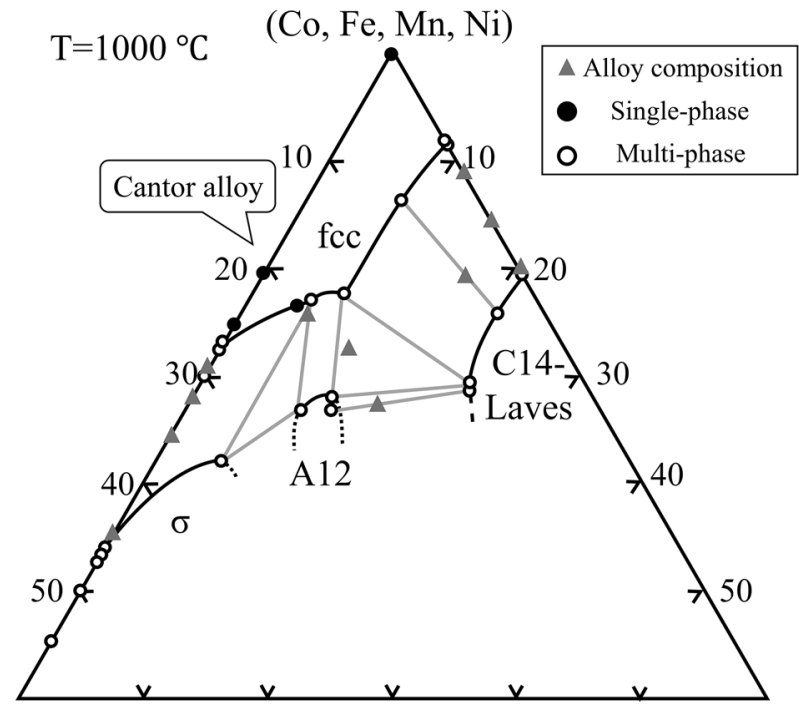

60 at. $\% \mathrm{Cr}$
60 at. $\% \mathrm{Ti}$

(a)

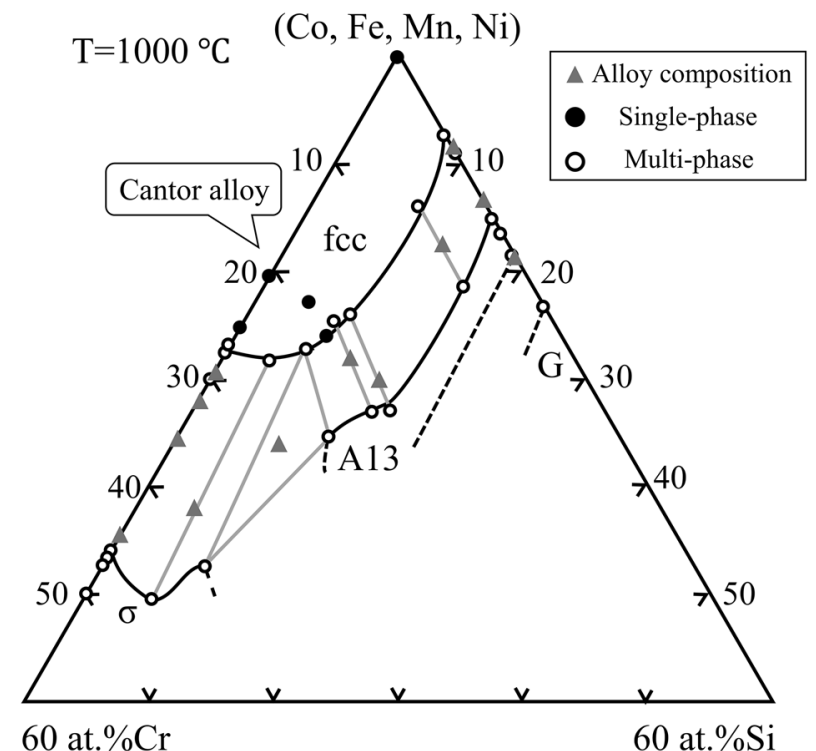

(b)

Figure 4: The phase relationship diagram of the alloys produced in this study. The projection of a (Co, $\mathrm{Fe}, \mathrm{Mn}, \mathrm{Ni})$ - equiatomic section of senary phase diagram with $\mathrm{Cr}$ and (a)Ti, (b)Si at $1000^{\circ} \mathrm{C}$, respectively. The black dots are a plot of the phase composition in single-phase alloys. The white ones are those in multi-phase alloys.

be a good index to select an additive element and a strengthening phase for the development of Cantor-based multi-phase alloys.

\section{Phase stability of each constituent phase}

In this study, the $\sigma$ phase, A12 phase, and C14-Laves phase are confirmed in Ti-added alloys (Fig. 4a), while the A13 phase is confirmed in Si-added alloys together with $\sigma$ phase and $\mathrm{G}$ phase (Fig. 4b). Ordered phases such as C14-Laves and $\sigma$ phases are composed of several elements occupying certain positions in crystals (Wyckoff positions). Additional elements may substitute for a certain site(s) in ordered structures [27-29]. Therefore, some phases found in high entropy alloys should be discussed in terms of the stabilization obtained by the addition of suitable substituting elements to a phase in its sub-system. Here, a sub-system means a lower-order system composed of some of its constituent elements. For example, the subsystem of $\mathrm{Co}-\mathrm{Fe}-\mathrm{Mn}-\mathrm{Ni}$ alloy are $\mathrm{Co}-\mathrm{Fe}-\mathrm{Mn}, \mathrm{Co}-\mathrm{Fe}-\mathrm{Ni}$ and $\mathrm{Fe}-\mathrm{Mn}-\mathrm{Ni}$ ternary systems, $\mathrm{Co}-\mathrm{Fe}, \mathrm{Co}-\mathrm{Mn}, \mathrm{Co}-\mathrm{Ni}, \mathrm{Fe}-\mathrm{Mn}, \mathrm{Fe}-\mathrm{Ni}$ and $\mathrm{Mn}-\mathrm{Ni}$ binary systems, and $\mathrm{Co}, \mathrm{Fe}, \mathrm{Mn}$ and $\mathrm{Ni}$ unary systems.

The C14-Laves phase is represented by $\mathrm{AB}_{2}$ in the compositional formula. Although there are three major variations, i.e., C14-Laves, C15-Laves, and C36-Laves, only their stacking sequences are different from each other [30]. As shown in Fig. $4 \mathrm{a}$, the solubility lobe of the C14-Laves phase is almost on a line along with constant $\mathrm{Ti}$ from the (Co, Fe, $\mathrm{Mn}, \mathrm{Ni})$-Ti edge. Among the binary sub-systems of the $\mathrm{Co}-\mathrm{Cr}-\mathrm{Fe}-\mathrm{Mn}-\mathrm{Ni}-\mathrm{Ti}$ system, except for the Ni-Ti system, Laves phases are found in Ti-containing systems [20]. Therefore, it can be concluded that $\mathrm{Ti}(\mathrm{Co}, \mathrm{Cr}, \mathrm{Fe}, \mathrm{Mn})_{2}$ might be expected to form a Laves phase, and $\mathrm{Ti}$ atoms mainly occupy the A-site. It is known that the stability of Laves-type phase is dominated by the atomic size difference between large A-site elements and small B-site elements [30-32]. The Laves phase has been confirmed in a wide range $1.05<r_{\mathrm{A}} / r_{\mathrm{B}}<1.68$, although the ideal size difference ratio is $r_{\mathrm{A}} / r_{\mathrm{B}}=1.225$, Here, $r_{\mathrm{A}}$ and $r_{\mathrm{B}}$ are the atomic radii of $\mathrm{A}$ and $\mathrm{B}$, respectively. The C.N. 12 atomic radii of $\mathrm{Co}, \mathrm{Cr}, \mathrm{Fe}, \mathrm{Mn}, \mathrm{Ni}$ and Ti are $0.125 \mathrm{~nm}, 0.128 \mathrm{~nm}, 0.127 \mathrm{~nm}, 0.126 \mathrm{~nm}, 0.125 \mathrm{~nm}$ and $0.146 \mathrm{~nm}$, respectively [33]. The atomic size of Ti is larger than that of the other elements, while the other elements have almost the same atomic radius. As mentioned above, there is no $\mathrm{TiNi}_{2}$ Laves phase; however, in some ternary systems containing $\mathrm{Ti}$ and $\mathrm{Ni}$, it is found that $\mathrm{Ni}$ can occupy the B-site of Laves phases $\mathrm{Ti}(\mathrm{Ni}, \mathrm{X})_{2}$ with $\mathrm{Co}, \mathrm{Cr}$, and Fe as $\mathrm{X}$ [34-38]. The fact that Ni can substitute on the B-site seems consistent with the fact that the $\mathrm{Ti}(\mathrm{Co}, \mathrm{Cr}, \mathrm{Fe}, \mathrm{Mn}, \mathrm{Ni})_{2}$ is found in the present study.

Because of its detrimental effect on the mechanical properties of structural materials such as stainless steels and Ni-based super alloys, a lot of research has been conducted on the stability of the $\sigma$ phase [39-41]. The $\sigma$ phase stability is thought to be dominated by $\overline{N_{v}}$, which is strongly related to the electron/ atom ratio e/a [40]. The $\sigma$ phase is found in Cr-based binary subs-system with $\mathrm{Co}, \mathrm{Fe}$, and $\mathrm{Mn}$, as discussed above, and also found in several ternary subsystems in which continuous solubility lobes have been reported [20, 34, 41, 42]. Although Ni, 
$\mathrm{Ti}$, and $\mathrm{Si}$ do not form $\sigma$ phase with $\mathrm{Cr}$ in their binary systems, it was reported that $\sigma$ phase is stabilized in $\mathrm{Cr}-\mathrm{Ni}-\mathrm{Si}$ ternary system and each element $(\mathrm{Ni}, \mathrm{Ti}$, and $\mathrm{Si}$ ) can be dissolved into Cr-based $\sigma$ phases in several ternary sub-systems composed of these elements [34, 42-44]. This must be one of the reasons why the multi-component $\sigma$ phase is stable in the vicinity of Cantor alloy with $\mathrm{Ti}$ or $\mathrm{Si}$.

The A12 phase in Ti-added alloys and A13 phase in Si-added alloys are recognized as the $\alpha \mathrm{Mn}$ structure and $\beta \mathrm{Mn}$ structure, respectively. As shown in Fig. 4b, the A13 phase in the senary system seems to start as a quinary phase at the $(\mathrm{Co}, \mathrm{Fe}, \mathrm{Mn}$, $\mathrm{Ni}$-Si edge. However, the A12 phase seems to be an intermediate phase having no connection to phases on the (Co, Fe, Mn, $\mathrm{Ni}$ )-Cr edge or (Co, Fe, Mn, Ni)-Ti edge (Fig. 4a). Now, let us discuss the trend of the stabilization of A12 and A13 phases in terms of additive elements. Interestingly, in binary systems, $\mathrm{Ti}$ addition to Mn stabilizes A12 ( $\alpha \mathrm{Mn}$ ), while Si addition stabilizes A13 ( $\beta \mathrm{Mn}$ ) [20]. This may suggest that Ti and Si have certain stabilizing effects on the A12 ( $\alpha \mathrm{Mn})$ and A13 ( $\beta \mathrm{Mn}$ ) phases, respectively. Ternary A12 $(\alpha \mathrm{Mn})$ phases are found in $\mathrm{Cr}-\mathrm{Mn}-\mathrm{Ti}$ and $\mathrm{Fe}-\mathrm{Mn}-\mathrm{Ti}$ ternary systems as random solid solution phases $[34,35,43,45]$. This means that $\mathrm{Cr}$ and $\mathrm{Fe}$ are helpful to stabilize the Mn-Ti A12 phase. In previous work, the quinary A12 phase was confirmed in the equiatomic CrFeMn$\mathrm{NiTi}$ alloy [46]. This suggests that co-doping of $(\mathrm{Fe}+\mathrm{Cr})$ also enhances the stability of the Mn-Ti A12 ( $\alpha \mathrm{Mn}$ ) phase. Also, some stable Mn-free A12 phases are found in its sub-systems. $\mathrm{Ti}_{5} \mathrm{Fe}_{16} \mathrm{Cr}_{8}$ and $\mathrm{Ti}_{7} \mathrm{Fe}_{35} \mathrm{Cr}_{13} \mathrm{Ni}_{3}$ intermetallic phases and the quinary intermetallic phase having a $\mathrm{Ti}_{5} \mathrm{Re}_{24}$-type ordered A12 $(\alpha \mathrm{Mn})$ phase were confirmed in the equiatomic CoCrFeNiTi alloy, while dis-ordered A12 phase was confirmed in Co-Cr-Ti ternary system [21, 34, 47-50]. From these points of view, $\mathrm{Co}, \mathrm{Cr}, \mathrm{Fe}$ and Ni can be expected to enhance the stability of an $\mathrm{A} 12(\alpha \mathrm{Mn})$ phase including a certain amount of Ti. Similarly, ternary A13 ( $\beta \mathrm{Mn}$ ) phases are found in Co-Mn-Si, $\mathrm{Fe}-\mathrm{Mn}-\mathrm{Si}$ and $\mathrm{Mn}-\mathrm{Ni}-\mathrm{Si}$ ternary systems as random solid solution phases [34, 35, 51]. Therefore, co-doping of (Co, Fe, Ni) into the Mn-Si A13 solid solution may stabilize the A13 phase strongly. This is consistent with the fact that quinary A13 phases in the $\mathrm{Co}-\mathrm{Fe}-\mathrm{Mn}-\mathrm{Ni}$-Si quinary system were confirmed in the present study. In addition, $\mathrm{Mn}$-free $\mathrm{Cr}_{3} \mathrm{Ni}_{5} \mathrm{Si}_{2}$ and $\mathrm{Ni}_{3} \mathrm{Fe}_{5} \mathrm{Si}_{2}$ phases having a $\mathrm{Au}_{4} \mathrm{Al}$-type ordered $\mathrm{A} 13$ structure have also been reported $[21,35,44]$. This suggests that $(\mathrm{Cr}+\mathrm{Ni})$ and $(\mathrm{Ni}+\mathrm{Fe})$ enhance the stability of the A13 structure with $\mathrm{Si}$. Figure 5 summarizes the above discussion. By combining the fragmental information on the stability of A12 and A13 phases in binary, ternary and higher-order sub-systems, it can be concluded that $\mathrm{Ti}$ or $\mathrm{Si}$ addition to the $\mathrm{Co}-\mathrm{Cr}-\mathrm{Fe}-\mathrm{Mn}-\mathrm{Ni}$ system stabilize the A12 or A13 structure, respectively. The detail of the effect of these key elements, $\mathrm{Ti}$ and $\mathrm{Si}$, might be clarified by careful investigation based on theoretical approaches such as first-principles calculations.

High-entropy alloys have been considered as single solid solution alloys, independent of the combination of the constituent elements, due to the large value of their configuration entropy $\Delta S_{\text {conf }}[1,52,53]$. However, a lot of studies have reported the existence of some intermetallic phases [54]. In general, the phase stability is described by the following Gibbs's free energy change $\Delta G$ :

$$
\Delta G=\Delta H-T \Delta S_{\text {conf }}
$$

$\Delta S_{\text {conf }}$ is defined by the Boltzmann equation:

$$
\Delta S_{\text {conf }}=-R \sum_{i=1}^{n} x_{i} \ln x_{i}
$$

Here, $\Delta H, T, R$, and $x_{i}$ are the enthalpy change, temperature, gas constant and the molar fraction of element $i$, respectively. As the number of components $n$ increases, the $\Delta S_{\text {conf }}$ term contributes to the increase of $\Delta G$. Hence, it is believed that a solid solution phase with random atomic arrangements becomes more stable with increasing $n$. In a similar manner, it can be expected that multi-component intermetallic compounds exhibit the $\Delta S_{\text {conf }}$ effect. When multiple elements occupy a certain atomic position, the combination of atomic arrangements, or $\Delta S_{\text {conf }}$, has a non-zero value. As discussed above, in Ti-added C14 Laves phase, $\mathrm{Ti}$ and the other elements may occupy the A-site and B-site, respectively. Hence, the compositional formula could be written simply as $\mathrm{Ti}(\mathrm{Co}, \mathrm{Cr}, \mathrm{Fe}, \mathrm{Mn}, \mathrm{Ni})_{2}$. A simple expression of total configuration entropy $\Delta S_{\text {conf }}^{\text {Total }}$ of the intermetallic compound $A_{a} B_{b}$ composed of two sites is as follows [55]:

$$
\Delta S_{\text {conf }}^{\text {Total }}=\frac{a}{a+b} \Delta S_{\text {conf }}^{A}+\frac{\mathrm{b}}{a+b} \Delta S_{\text {conf }}^{B}
$$

Here, $\Delta S_{\text {conf }}^{A}$ and $\Delta S_{\text {conf }}^{B}$ are $\Delta S_{\text {conf }}$ in the A-site and B-site, respectively. The estimated $\Delta S_{\text {conf }}^{\text {Total }}$ of $\mathrm{Ti}(\mathrm{Co}, \mathrm{Cr}, \mathrm{Fe}, \mathrm{Mn}, \mathrm{Ni})_{2}$ is $1.07 R$ by assuming that the ratio of constituent elements in the B-site is equiatomic and that the A-site is occupied only by $\mathrm{Ti}$. This value is comparable to that of about $60 \%$ for an equiatomic senary solid solution phase $\left(\Delta S_{\text {conf }}=1.79 R\right)$, and $2 / 3$ of the value for the equiatomic Cantor alloy. This estimation is conducted on stoichiometric $\mathrm{Ti}(\mathrm{Co}, \mathrm{Cr}, \mathrm{Fe}, \mathrm{Mn}$, $\mathrm{Ni})_{2}$. However, as shown in Online Resource 3, the Ti content of the Laves phase confirmed in this study deviates from its stoichiometric composition (33.3 at.\%). Therefore, the $\Delta S_{\text {conf }}$ for the A-site can also be a non-zero value. It is suggested the combination of the non-negligible entropy effect with the strong enthalpy effect can potentially stabilize an intermetallic phase with ordered atomic arrangement in a multi-component system. Although $\sigma, \mathrm{A} 12(\alpha \mathrm{Mn})$ and $\mathrm{A} 13(\beta \mathrm{Mn})$ phases have several Wycoff positions, it is considered that there is no 


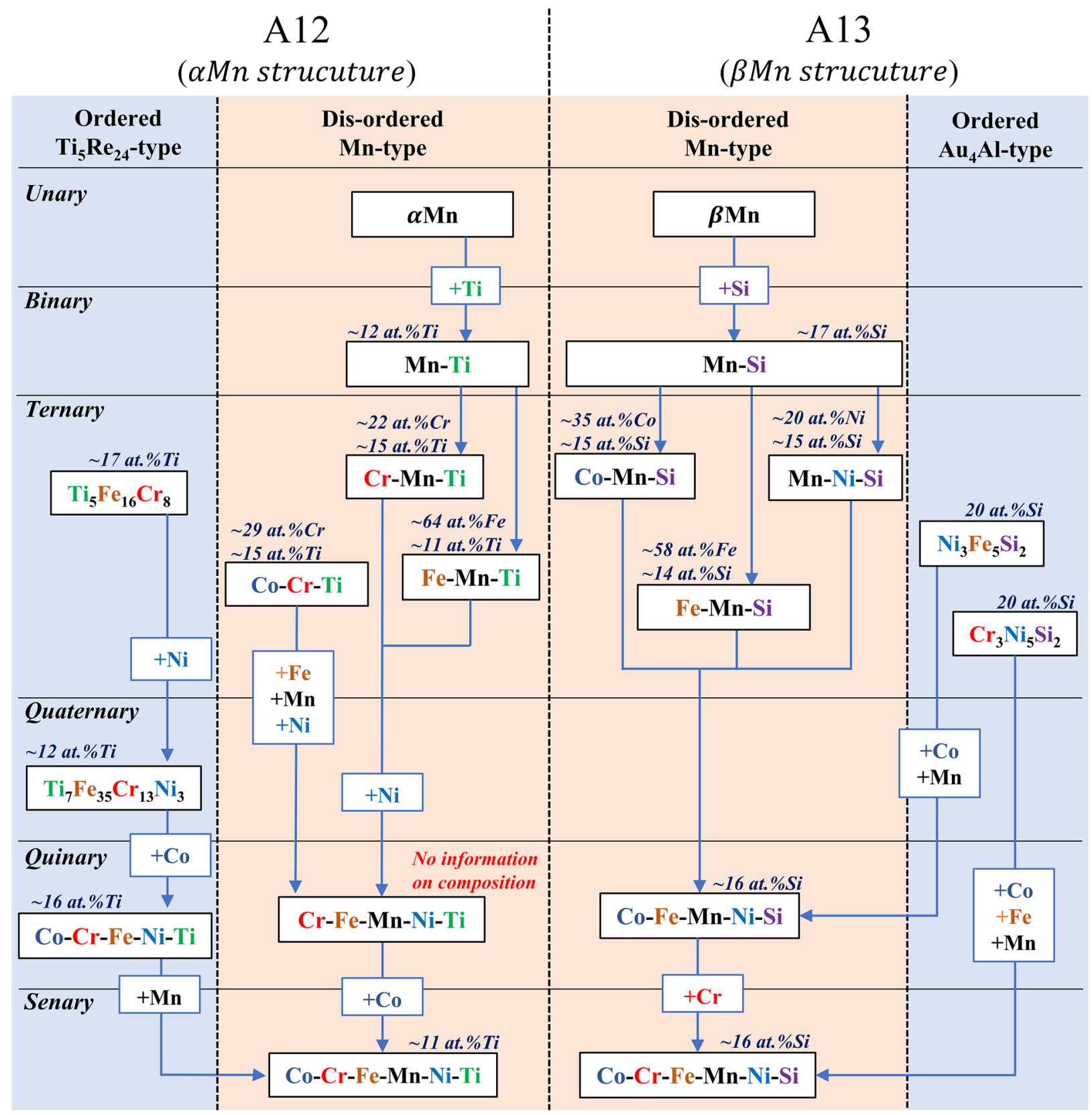

Figure 5: Phase relationship between senary A12 or A13 phases and their sub-system phases. A12 and A13 phases in pure-Mn can be connected to A12 and A13 phases in senary system by the dissolution of other constituent elements, respectively. Phase information was obtained from Ref. [20, 21, 34, 35, 42-51].

specific occupying element for each site [21]. Thus, if constituent elements are equally distributed in each position, these phases can have the same $\Delta S_{\text {conf }}$ values as simple solid solution phases, such as fcc, bcc and hcp. In Fig. 5, it is found that senary A12 and A13 phases are formed by combinations of elements that have a strong tendency to form them in their sub-systems, i.e., strong atomic interactions. It also suggests that the combination of a non-negligible enthalpy effect with a strong entropy effect can potentially stabilize these phases in multi-component systems, such as $\sigma, \mathrm{A} 12(\alpha \mathrm{Mn})$ and A13 ( $\beta$ $\mathrm{Mn})$ phases without an ordered atomic arrangement.

\section{Tensile properties}

As shown in Online Resource 6, the homogenized alloys \#25, \#26T and \#27S were confirmed to be fcc single solid solution 
alloys. This result is consistent with the phase equilibrium information shown in Fig. 4 (See Online Resource 7 for the electron backscatter diffraction (EBSD) images of recrystallized microstructure in alloys \#25, \#26T, and \#27S). Each sample has a fully recrystallized microstructure with a large density of annealing twins. The average grain diameter without twin boundaries of alloys \#25, \#26T and \#27S measured by a linear-intercept method is $35.7,32.6$, and $47.7 \mu \mathrm{m}$, respectively. The grain sizes of \#25 and \#26T are almost the same or smaller than that of \#27S. The number of twin boundaries per grain of alloys \#25, \#26T and \#27S are 1.09, 1.01 and 1.05, respectively. There was no significant difference in the annealing twin density of different samples.

Figure 6 shows the engineering stress-strain curve. (See Online Resource 8 for the value of strength and ductility) Both $0.2 \%$ yield stress and ultimate tensile strength increase in the order of \#25, \#27S, and \#26T. The ductility of alloy \#27S is higher than that of alloys \#25 and \#26T.

Now let us assume the strength of materials can be expresses by a simple sum of the strengthening terms such as grain refinement strengthening and solid solution strengthening of the alloys. The Hall-Petch relationship for the effect of grain size on the yield strength $\sigma_{y}$ is well known and is expressed by the following equation [56]:

$$
\sigma_{y}=\sigma_{0}+k d^{-0.5}
$$

Here, $\sigma_{0}, k$, and $d$ are the intercept, Hall-Petch coefficient and grain diameter, respectively. Otto et al. reported Hall-Petch equation of Cantor alloy at room temperature to be $\sigma_{y}=$ $125+494 d^{-0.5} \mathrm{MPa}$ [3]. Figure 7 shows Hall-Petch plot of the $0.2 \%$ yield strength on alloys \#25,\#26T, and \#27S. The yield

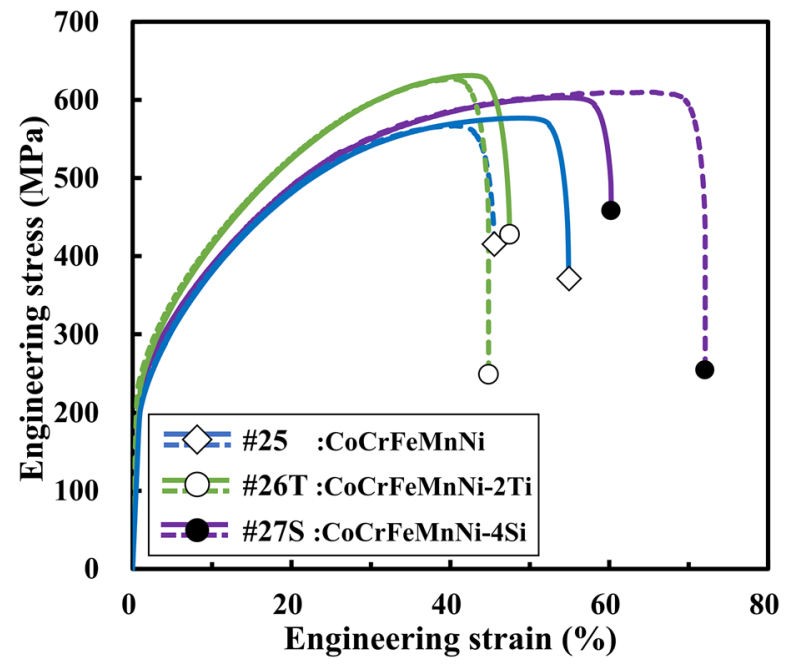

Figure 6: Engineering stress-strain curve of alloys \#25, \#26T, and \#27S, annealed for $15 \mathrm{~min}$ at $1000^{\circ} \mathrm{C}$ after homogenization and cold-rolling. Broken curves and solid curves indicate the results of "Specimen 1" and "Specimen 2", respectively.

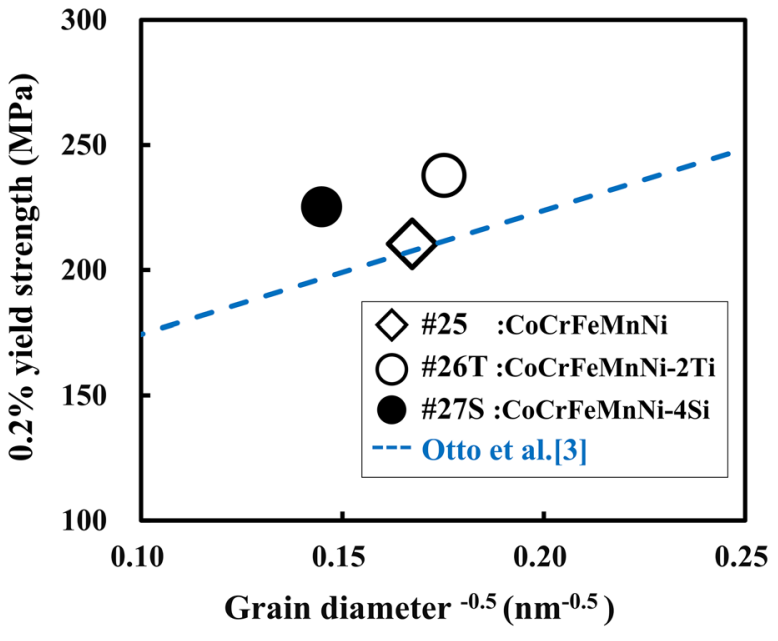

Figure 7: Hall-Petch plot of $0.2 \%$ yield strength of alloy \#25, \#26T, and $\# 27 \mathrm{~S}$. The broken line corresponds to $\sigma_{y}=125+494 d^{-0.5}$, which is the Hall-Petch relationship of the CoCrFeMnNi high entropy alloy reported by Otto et al. [3].

strength of \#25 is on Otto's line. By assuming that the $k$ value does not largely change with an extra element dissolution, the difference between the yield stress of alloy \#26T and that of the Cantor alloy having the same grain size as alloy \#26T is estimated to be $26.3 \mathrm{MPa}$, and 28.8 MPa for alloy \#27S. Although the amount of $\mathrm{Si}$ in alloy \#27S is larger than that of $\mathrm{Ti}$ in alloy $\# 26 \mathrm{~T}$, the solid solution strengthening value of \#26T is almost the same as that of \#27S.

There are various models proposed to account for the solid solution strengthening in high entropy alloys by additive elements in the terms of the change in the shear modulus $\varepsilon_{\mathrm{G}}$ and lattice distortion $\varepsilon_{\mathrm{a}}$ [57-60]. In the present study, we applied the following equation within the framework of the strengthening model for conventional dilute alloys:

$$
\Delta \sigma_{\mathrm{ss}}=A \cdot c^{n} \cdot \varepsilon_{\mathrm{a}}^{m}
$$

Here, $\Delta \sigma_{\text {ss }}$ is the amount of solid solution strengthening, $A$ is a constant including several terms such as the Taylor factor and shear modulus, $n$ and $m$ are arbitrary numbers, and $c$ is the mole fraction of the solute atom, respectively. For conventional dilute alloys, Fleischer applied $n=1 / 2$ and $m=3 / 2$, while Labusch applied $n=2 / 3$ and $m=4 / 3[56,61,62] . \varepsilon_{a}$ was estimated using the following equation.

$$
\varepsilon_{\mathrm{a}}=\left|\frac{1}{a_{0}} \frac{d a}{d c}\right|
$$

Here, $a_{0}$ is the lattice constant of equiatomic CoCrFeMnNi alloy.

The effect of $\mathrm{Ti}$ and $\mathrm{Si}$ on the lattice constant of equiatomic CoCrFeMnNi alloys (alloys \#11T, \#19S, \#20S, \#25, \#26T, and $\# 27 \mathrm{~S}$ ) are presented in Online Resource 9. It is clearly shown that both $\mathrm{Ti}$ and $\mathrm{Si}$ change the lattice constant linearly, although 
$\mathrm{Ti}$ increases the lattice constant and Si decreases. By applying the lattice constant $a_{0}=0.3605 \mathrm{~nm}$ of equiatomic $\mathrm{CoCrFeMnNi}$ alloy (alloy \#25), $\varepsilon_{a}$ for Ti addition is evaluated to be $6.52 \%$, while that for $\mathrm{Si}$ addition is $1.91 \%$, respectively.

The relationship between $\Delta \sigma_{\mathrm{ss}} / c^{n}$ and $\varepsilon_{\mathrm{a}}^{m}$ of our results are plotted in Online Resource 10 with several combinations of $n$ and $m$, together with results of several previous works $[14,17]$. Although our data on 2 at.\% Ti and 4 at.\%Si addition seems to have a positive correlation between $\Delta \sigma_{\mathrm{ss}} / c^{n}$ and $\varepsilon_{\mathrm{a}}^{m}$, the solid solution strengthening in 2 at.\%Ti-added alloy, which is estimated from the experimental results of Shahmir et al., is much larger than our result [14]. Moreover, the estimated value of solid solution strengthening with $\mathrm{Al}$ addition, estimated by subtracting the grain size effect from the reported strength, was also plotted [17]. The $\varepsilon_{\mathrm{a}}$ of $\mathrm{Al}$ addition was estimated from the lattice constant change reported by [17], using the same method as described above. Although the $\varepsilon_{\mathrm{a}}$ of $\mathrm{Al}$ addition is larger than that of $\mathrm{Ti}$ and $\mathrm{Si}$ addition, the solid solution strengthening is obviously smaller. These results suggest no apparent positive correlation among the various additive elements exists in any of the combinations of $\mathrm{n}$ and $\mathrm{m}$. This inconsistency might be attributed to several reasons such as the inhomogeneity of alloys [17], the difference of texture formed during alloy processing [14], and other factors affecting dislocation motion such as the formation of short-range clusters and difference in short-range ordering tendencies $[3,63,64]$.

In Fig. 6, alloy \#26T shows similar ductility as alloy \#25, while alloy \#27S has obviously higher ductility. According to the mechanical instability, the local necking of the tensile specimen starts when the strain hardening rate $d \sigma_{\mathrm{t}} / d \varepsilon_{\mathrm{t}}$ is equal to

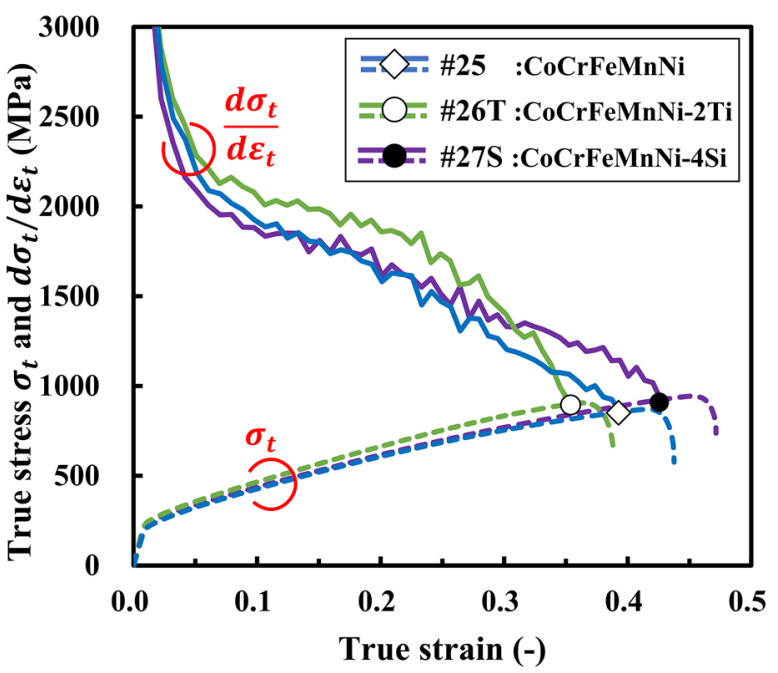

Figure 8: The plot of strain hardening rate $d \sigma_{\mathrm{t}} / d \varepsilon_{\mathrm{t}}$ on the true stressstrain curve of alloy \#25, \#26T, and \#27S, indicated by broken curves. Each curve shows the results of "Specimen 2". Symbols indicate the intersection of strain hardening curve and true stress-strain curve. $\sigma_{\mathrm{t}}$. Here, $\sigma_{\mathrm{t}}$ and $\varepsilon_{\mathrm{t}}$ are true stress and true strain, respectively. Figure 8 shows the plot of $d \sigma_{\mathrm{t}} / d \varepsilon_{\mathrm{t}}$ against true strain with the true stress-strain curve. Each curve corresponds to the results of "Specimen 2" of each alloy, however, the results are consistent with that of "Specimen 1". Each true strain at the intersection of the strain hardening curve and the true stress-strain curve corresponds to the engineering strain at the ultimate tensile strength in Fig. 6. From these results, it is found that the ductility of these alloys is dominated by plastic instability, and the higher $d \sigma_{t} / d \varepsilon_{t}$ results in better elongation.

It has been reported that Cantor alloy shows twin formation during tensile tests at $77 \mathrm{~K}[3,12,65]$. The increase in twin boundaries results in the increase of strength by the pile-up of dislocation, i.e., twin formation can be a reason for the increase of the $d \sigma_{\mathrm{t}} / d \varepsilon_{\mathrm{t}}$ during plastic deformation, resulting in the large elongation at $77 \mathrm{~K}$. On the other hand, the twinning during plastic deformation at room temperature occurs only near the necking part of the specimens $[65,66]$. Online Resource 11 shows EBSD maps near the necking part of "Specimen 2" to compare with the result shown in Fig. 8. It is obvious that the twin boundaries in alloys \#25 and \#27S are much more than in \#26T. It strongly suggests that $\mathrm{Si}$ addition keeps the twin formation tendencies, but Ti addition doesn't. Although there is no report on the effect of Ti and Si on the stacking fault energies in the Cantor alloy, the $\mathrm{Si}$ addition to some of the alloys in the subsystems such as $\mathrm{Co}-\mathrm{Cr}-\mathrm{Ni}$ and $\mathrm{Fe}-\mathrm{Mn}$ results in the low stacking fault energies [67-69]. The twinning tendencies of Cantor-based alloy by Si addition might be one of the reasons for the good ductility at room temperature of Cantor-based alloy, however, further experimental and/or theoretical studies are needed to clarify the detail of the mechanisms to increase $d \sigma_{t} / d \varepsilon_{t}$.

It was found that both $\mathrm{Ti}$ - and $\mathrm{Si}$-added alloys show higher strength and maintain the similar or better ductility than Cantor alloys (Fig. 6). The introduction of a second phase into these ductile matrixes will provide a further increase in its strength. In this way, Cantor-based multi-phase alloys with a better strengthductility balancing may be developed. As the next step, it is necessary to investigate the mechanical properties of multi-phase alloys with dispersed strengthening phases whose volume fraction and morphology are controlled by the phase diagram proposed in the present study.

\section{Conclusion}

An investigation on phase equilibrium in $\mathrm{Co}-\mathrm{Fe}-\mathrm{Mn}-\mathrm{Ni}-\mathrm{Cr}-\mathrm{Ti}$ or Si senary systems was conducted by microstructure observation and XRD analysis of several Cantor-based alloys with Ti or $\mathrm{Si}$ addition annealed for $168 \mathrm{~h}$ at $1000^{\circ} \mathrm{C}$. In order to understand the effect of $\mathrm{Ti}$ or Si dissolution on the mechanical properties, tensile tests were conducted at room temperature with a strain rate of $\dot{\varepsilon}=1.0 \times 10^{-3} \mathrm{~s}^{-1}$ on tensile specimens machined from 
fully recrystallized sheets of Cantor-based fcc single solid solution alloys with Ti or Si addition. The authors obtained the following conclusions.

1. Ti addition stabilizes the $\sigma, \mathrm{A} 12$ and C14-Laves phases at $1000^{\circ} \mathrm{C}$, while $\mathrm{Si}$ addition stabilizes the $\mathrm{A} 13$ phase. Cr addition stabilizes the $\sigma$ phase in either system.

2. The projection of the composition of alloys and phases on a ternary phase diagram expression of the equiatomic $\mathrm{Co}-\mathrm{Fe}-\mathrm{Mn}-\mathrm{Ni}$ section with $\mathrm{Cr}$ corner and additive element corner is quite useful to understand the relationship between the phase equilibrium among phases.

3. The stabilization of A12, A13, C14-Laves and $\sigma$ phases is discussed based on the fragmental information on the stabilization of corresponding phases in the sub-systems by the addition of constituent elements.

4. Both $\mathrm{Ti}$ addition and $\mathrm{Si}$ addition improve the tensile strength of Cantor alloy. The ability of strengthening of $\mathrm{Ti}$ addition is larger than that of $\mathrm{Si}$ addition. Ti addition results in a rather low ductility of alloy than that of Cantor alloy. The difference in ductility is related to their strain hardening behavior in the higher strain range.

\section{Experimental procedure}

The purity of each raw material was at least $99.9 \%$. In order to minimize the evaporation of $\mathrm{Mn}$ with a high vapor pressure during arc melting, and to prevent remaining of the un-melted $\mathrm{Cr}$ with a high melting point, the melting methods were carefully selected and conducted. Series No.1 alloys \#2 \#6 and all series No.3 alloys, which contained both $\mathrm{Cr}$ and $\mathrm{Mn}$, were prepared from a master ingot of the 20 at.\%Co- 20 at.\%Cr- 20 at.\%Fe20 at.\%Mn- 20 at.\%Ni alloy (\#0) produced by induction melting. After some pieces of alloy \#0 were cut from the ingot, $\mathrm{Si}, \mathrm{Ti}$ and $\mathrm{Cr}$ were added by arc melting. Alloy \# 1 and all of the series No.2 alloys were produced only by arc melting. The series No.5 alloys, which contained higher amount of $\mathrm{Cr}$ and $\mathrm{Mn}$, were produced by arc melting by adding other elements into the piece of 13 at.\%Co- 50 at.\%Cr- 13 at.\%Fe- 20 at.\%Mn- 4 at.\%Ni master alloy produced by induction melting. The series No.4 alloys were produced only by induction melting.

Induction melting was conducted under an Ar gas atmosphere to a pressure of $\sim 2.0 \times 10^{4} \mathrm{~Pa}$ after the chamber was evacuated up to $\sim 2.7 \times 10^{-3} \mathrm{~Pa}$. Raw materials with a total weight of $\sim 200 \mathrm{~g}$ were loaded in an alumina or magnesia crucible. After melting over $10 \mathrm{~min}$, the molten alloy was cast into an S45C mild steel mold coated with boron nitride. Arc melting was conducted under an Ar gas atmosphere to a pressure of $\sim 6.0 \times 10^{4} \mathrm{~Pa}$ after the chamber was evacuated up to $\sim 6.7 \times 10^{-3} \mathrm{~Pa}$. Materials with a total weight of $2 \sim 7 \mathrm{~g}$ were loaded in a water-cooled $\mathrm{Cu}$ hearth. The buttons were flipped and re-melted at least five times with a Ti getter melting once every four melts. The species of all ingots were cut from the ingots, encapsulated in evacuated quartz ampules, and annealed for $168 \mathrm{~h}$ at $1000^{\circ} \mathrm{C}$ followed with water-quenching.

The homogenized samples of alloys \#25, \#26T and \#27S were cut into $\approx 45 \times 15 \times 10 \mathrm{~mm}$ blocks, then cold-rolled until the final thickness was $\approx 1.3 \mathrm{~mm}$. The rolling was not only done in the longitudinal direction but also in the perpendicular direction so that its width was $\approx 30 \mathrm{~mm}$. This corresponds to a reduction rate of $87 \%$. Next, the dog-bone shaped tensile specimens were machined from these cold-rolled sheets by electrical discharge machining. After being ground on each side with $\mathrm{SiC}$ paper to remove the damaged layer during machining, the tensile specimens were encapsulated and annealed for $15 \mathrm{~min}$ at $1000^{\circ} \mathrm{C}$. After quenching, the recrystallized specimens were ground again to remove the oxidation layer. Finally, the measured gauge length, width, and thickness of the specimen were about $16 \mathrm{~mm}, 1.9 \mathrm{~mm}$ and $0.9 \mathrm{~mm}$, respectively. Tensile tests were conducted at an engineering strain rate of $1.0 \times 10^{-3} \mathrm{~s}^{-1}$ with a screw-driven Instron-type machine (AG-50kND, SHIMADZU). Two tests were done for each alloy type at room temperature called "Specimen 1 " and "Specimen 2". The displacement of the crosshead was used as the tensile displacement value of the specimen.

XRD measurement (Philips X' PERT MPD) was conducted at room temperature with $\mathrm{Cu}-\mathrm{K} \alpha$ at $40 \mathrm{kV}$ and $40 \mathrm{~mA}$ on the bulk samples of each alloy polished with $\mathrm{SiC}$ paper. For brittle alloys \#9T, \#17S, \#28T and \#29T, the powders of samples crushed with a tungsten carbide mortar were used. The composition analysis and microstructure observation were carried out with field emission EPMA (JXA-8530F, JEOL) for the samples polished using $\mathrm{SiC}$ paper, $\mathrm{Al}_{2} \mathrm{O}_{3}$ powder $(0.1 \mu \mathrm{m})$, and colloidal silica. EBSD analysis was carried out in a field emission scattered electron microscope (JSM-6500F, JEOL) and analyzed by "OIM Data Collection 7 and OIM Analysis 7 (TSL solutions)" software. The step size was set to $0.1 \mu \mathrm{m}$ for observing the recrystallized microstructure and $0.01 \mu \mathrm{m}$ for observing the microstructure after deformation. The ingots of master alloys and alloys \#25, \#26T, and \#27S were confirmed by X-ray Fluorescence analysis (JSX-3100RII, JEOL) to have no compositional segregation between the upper and bottom sides. 


\section{Acknowledgments}

A part of this work was conducted at "Joint-use Facilities: Laboratory of Nano-Micro Material Analysis", Hokkaido University, supported by "Nanotechnology Platform" Program of the Ministry of Education, Culture, Sports, Science and Technology (MEXT), Japan.

\section{Author contributions}

All authors contributed to the study conception and design. Material preparation, data collection and analysis were performed by SY, KI and SM. The first draft of the manuscript was written by SY and all authors commented on previous versions of the manuscript. All authors read and approved the final manuscript.

\section{Data availlability}

The datasets generated during and/or analyzed during the current study are available from the corresponding author on reasonable request.

\section{Declarations}

Conflict of interest The authors have no conflicts of interest directly relevant to the content of this article.

\section{Supplementary Information}

The online version contains supplementary material available at https://doi.org/10.1557/s43578-021-00251-0.

\section{Open Access}

This article is licensed under a Creative Commons Attribution 4.0 International License, which permits use, sharing, adaptation, distribution and reproduction in any medium or format, as long as you give appropriate credit to the original author(s) and the source, provide a link to the Creative Commons licence, and indicate if changes were made. The images or other third party material in this article are included in the article's Creative Commons licence, unless indicated otherwise in a credit line to the material. If material is not included in the article's Creative Commons licence and your intended use is not permitted by statutory regulation or exceeds the permitted use, you will need to obtain permission directly from the copyright holder. To view a copy of this licence, visit http://creativecommons.org/ licenses/by/4.0/.

\section{References}

1. J.W. Yeh, S.K. Chen, S.J. Lin, J.Y. Gan, T.S. Chin, T.T. Shum, C.H. Tsau, S.Y. Chang, Adv. Eng. Mater. 6(5), 299 (2004). https://doi. org/10.1002/adem.200300567

2. B. Cantor, I. Chang, O. Knight, A.J.B. Vincent, Mater. Sci. Eng. A. 375-377, 213 (2004). https://doi.org/10.1016/j.msea.2003.10.257

3. F. Otto, A. Dlouhý, C. Somesen, H. Bei, G. Eggeler, E.P. George, Acta. Mater. 61(15), 5743 (2013). https://doi.org/10.1016/j.actam at.2013.06.018

4. Z. Wu, H. Bei, G.M. Pharr, E.P. George, Acta. Mater. 81, 428 (2014). https://doi.org/10.1016/j.actamat.2014.08.026

5. K. K. Tseng, C. C. Juan, S. Tso, H. C. Chen, C. W. Tsai, J. W. Yeh, Entropy. 21(1), 1 (2019) https://doi.org/10.3390/e21010015

6. O.N. Senkov, G.B. Wilks, J.M. Scott, D.B. Miracle, Intermetallics 19(5), 698 (2011). https://doi.org/10.1016/j.intermet.2011.01.004

7. O.N. Senkov, J.M. Scott, S.V. Senkova, D.B. Miracle, C.F. Woodward, J. Alloys Compd. 509(20), 6043 (2011). https://doi.org/10. 1016/j.jallcom.2011.02.171

8. T. Yang, Y.L. Zhao, Y. Tong, Z.B. Jiao, J. Wei, J.X. Cai, X.D. Han, D. Chen, A. Hu, J.J. Kai, K. Lu, Y. Liu, C.T. Liu, Science 362, 933 (2018). https://doi.org/10.1126/science.aas8815

9. Z. Guo, A. Zhang, J. Han, J. Meng, J. Mater. Sci. 54, 5844-5851 (2019). https://doi.org/10.1007/s10853-018-03280-z

10. Z. Li, C.C. Tasan, K.G. Pradeep, D. Rabbe, Acta. Mater. 131, 323 (2017). https://doi.org/10.1016/j.actamat.2017.03.069

11. P. Shi, W. Ren, T. Zheng, Z. Ren, X. Hou, J. Peng, P. Hum Y. Gao, Y. Zhong, P. K. Liaw, Nat. Commun. 10, 489 (2019). https://doi. org/10.1038/s41467-019-08460-2

12. B. Gludovatz, A. Hohenwarter, D. Catoor, E. H. Chamg. E. P. George, R. O. Rithie, Science. 345(6201), 1153 (2014). https:// doi.org/10.1126/science.1254581

13. G. Qin, Z. Li, R. Chen, H. Zheng, C. Fan, L. Wang, Y. Su, H. Ding, J. Guo, H. Fu, J. Mater. Res. 34(6), 1011 (2019). https://doi. org/10.1557/jmr.2018.468

14. H. Shahmir, M. Nili-Ahmadabadi, A. Shadiee, M. Andrzejczuk, M. Lewandowska, T.G. Langdo, Mater. Sci. Eng. A. 725, 196 (2018). https://doi.org/10.1016/j.msea.2018.04.014

15. G. Qin, R. Chen, H. Zheng, H. Fang, L. Wang, Y. Su, J. Guo, H. Fu, J. Mater. Sci. Technol. 35(4), 578 (2019). https://doi.org/10. 1016/j.jmst.2018.10.009

16. C. Wang, T.H. Ki, Y.C. Li, J.S.H. Jang, C.H. Hsueh, Mater. Sci. Eng. A. 764(9), 138192 (2019). https://doi.org/10.1016/j.msea. 2019.138192

17. J.Y. He, W.H. Liu, H. Wang, Y. Wu, X.J. Liu, T.G. Nieh, Z.P. Liu, Acta. Mater. 62(1), 105 (2014). https://doi.org/10.1016/j.actamat. 2013.09.037 
18. Z. Li, Acta. Mater. 164(1), 400 (2019). https://doi.org/10.1016/j. actamat.2018.10.050

19. N.D. Stepanov, D.G. Shaysultanov, G.A. Salishchev, M.A. Tikhonovsky, E.E. Oleynik, A.S. Tortika, O.N. Senko, J. Alloys Compd. 628(15), 170 (2015). https://doi.org/10.1016/j.jallcom. 2014.12.157

20. H. Okamoto, DESK Handbook: Phase diagram for Binary Alloys, 2nd edn. (ASM international, Ohio, 2010)

21. P. Villars, K. Cenzual, Pearson's Crystal Data - Crystal Structure Database for Inorganic Compounds (on DVD), Release 2014/15, ASM International, Materials Park

22. E. Haccuria, T. Crivits, P.C. Hayes, E. Jak, J. Am. Ceram. Soc. 99(2), 691 (2016). https://doi.org/10.1111/jace.13991

23. F. Otto, A. Dlouhý, K.G. Pradeep, M. Kuběnová, D. Raabe, G. Eggeler, E.P. George, Acta. Mater. 112, 40 (2016). https://doi.org/ 10.1016/j.actamat.2016.04.005

24. M.V. Klimova, D.G. Shaysultanov, S.V. Zherebtsov, N.D. Stepanov, Mater. Sci. Eng. A. 748, 228 (2019). https://doi.org/10. 1016/j.msea.2019.01.112

25. G. Laplanche, S. Berglund, C. Reinhart, A. Kostka, F. Fox, E.P. George, Acta. Mater. 161, 338 (2018). https://doi.org/10.1016/j. actamat.2018.09.040

26. Z. Wu, H. Bei, F. Otto, G.M. Pharr, E.P. George, Intermetallics 46 , 131 (2014). https://doi.org/10.1016/j.intermet.2013.10.024

27. S. Ochiai, Y. Oya, T. Suzuki, Acta. Metall. 32(2), 289 (1984). https://doi.org/10.1016/0001-6160(84)90057-9

28. V. Raghavan, J. Phase. Equilibria. Diffus. 30(2), 199 (2009). https://doi.org/10.1007/s11669-009-9492-3

29. L. Peng, S. Takizawa, K. Ikeda, T. Horiuchi, S. Miura, Intermetallics 110, 106457 (2019). https://doi.org/10.1016/j.intermet.2019. 03.020

30. F. Stein, M. Palm, G. Sauthoff, Intermetallics 12, 713 (2004). https://doi.org/10.1016/j.intermet.2004.02.010

31. J.H. Zhu, C.T. Liu, L.M. Pike, P.K. Liaw, Intermetallics 10, 579 (2002). https://doi.org/10.1016/S0966-9795(02)00030-4

32. T. Yamanouchi, S. Miura, Mater. Trans. 59(4), 546 (2018). https:// doi.org/10.2320/matertrans.MJ201604

33. W.B. Pearson, The Crystal Chemistry and Physics of Metals and Alloys, 1st edn. (Wiley, New York, 1972), p. 151

34. P. Villars, A. Prince, H. Okamoto. Handbook of Ternary Alloy Phase Diagrams, vol. 7, 1st edn. (ASM international, Ohio, 1995)

35. P. Villars, A. Prince, H. Okamoto. Handbook of Ternary Alloy Phase Diagrams, vol. 8, 1st edn. (ASM international, Ohio, 1995)

36. C. Zhou, C. Guo, C. Li, Z. Du, CALPHAD 63, 61 (2018). https:// doi.org/10.1016/j.calphad.2018.08.011

37. Y.H. Tan, H.H. Xu, Y. Du, Trans. Nonferrous Met. Soc. China. 17(4), 711 (2007). https://doi.org/10.1016/S1003-6326(07) 60161-7

38. L.I. Duarte, U.E. Klotz, C. Leienbach, M. Palm, F. Stein, J.F. Löffler, Intermetallics 18(3), 374 (2010). https://doi.org/10.1016/j. intermet.2009.08.008
39. J.M. Joubert, Prog. Mater. Sci. 53, 528 (2008). https://doi.org/10. 1016/j.pmatsci.2007.04.001

40. B. Seiser, R. Drautz, D.G. Pettifor, Acta. Mater. 59, 749 (2011). https://doi.org/10.1016/j.actamat.2010.10.013

41. C.T. Sims, JOM 21(12), 27 (1969). https://doi.org/10.1007/BF033 78800

42. P. Villars, A. Prince, H. Okamoto. Handbook of Ternary Alloy Phase Diagrams, vol. 6, 1st edn. (ASM international, Ohio, 1995)

43. L.Y. Chen, C.H. Li, K. Wang, H.Q. Dong, X.G. Lu, W.Z. Ding, CALPHAD 33(4), 658 (2009). https://doi.org/10.1016/j.calphad. 2009.08.002

44. X. Liu, M. Lin, S. Yang, J. Ruan, C. Wang, J. Phase Equilibria. Diffus. 35, 334 (2014). https://doi.org/10.1007/s11669-014-0279-9

45. A. Walnsch, M.J. Kriegel, O. Fabrichnaya, A. Leineweber, J. Phase Equilibria. Diffus. 41, 457 (2020). https://doi.org/10.1007/ s11669-020-00804-6

46. F. Otto, Y. Yang, H. Bei, E.P. George, Acta Mater. 61, 2628 (2013). https://doi.org/10.1016/j.actamat.2013.01.042

47. L. Zeng, L. Liu, S. Huang, L. Zhang, CALPHAD 58, 58 (2017). https://doi.org/10.1016/j.calphad.2017.05.006

48. K.P. Gupta, J. Phase Equilibria. 22, 52 (2001). https://doi.org/10. 1361/105497101770339292

49. M. Tsai, A. Fan, H. Wang, J. Alloys. Compd. 695, 1479 (2017) https://doi.org/10.1016/j.jallcom.2016.10.286

50. H. Hughes, D.T. Llewelyn, J. Iron. Steel. Inst. 192, 170 (1959)

51. P. Villars, A. Prince, H. Okamoto. Handbook of Ternary Alloy Phase Diagrams, vol. 10, 1st edn. (ASM international, Ohio, 1995)

52. B.S. Murty, J.W. Yeh, S. Ranganathan, High Entropy Alloys, 1st edn. (Elsevier, London, 2014), pp. 13-35

53. J.W. Yeh, JOM 65(12), 1759 (2013). https://doi.org/10.1007/ s11837-013-0761-6

54. M. H. Tsai, R. C. Tsai, T. Chang, W. F. Huang, Metals 9, 247 (2019) https://doi.org/10.3390/met9020247

55. T. Nishizawa, Thermodynamics of Microstructures, 1st edn. (ASM international, Ohio, 2010), pp. 67-71

56. J. P. Hirth, J. Lothe. Theory of Dislocations, 3rd. edn. (Cambridge University Press, New York, 2017), pp.522-525, 606-607

57. I. Toda-Caraballo, J.S. Wróbel, S.L. Dudarev, D. Nguyen-Manh, P.E.J. Rivera-Díaz-del-Castillo, Acta Mater. 97(15), 156 (2015). https://doi.org/10.1016/j.actamat.2015.07.010

58. C. Varvenne, W.A. Curtin, Scr. Mater. 138, 92 (2017). https://doi. org/10.1016/j.scriptamat.2017.05.035

59. M. Agustianingrum, S. Yoshida, B. Tsuji, N. Park, J. Alloys Compd. 781, 866 (2019). https://doi.org/10.1016/j.jallcom.2018. 12.065

60. S. Yoshida, T. Ikeuchi, T. Bhattacharjee, Y. Bai, A. Shibata, N. Tsuji, Acta Mater. 171, 201 (2019). https://doi.org/10.1016/j. actamat.2019.04.017

61. R.L. Fleischer, Acta metall. 11(3), 203 (1963). https://doi.org/10. 1016/0001-6160(63)90213-X 
62. R. Labusch, Phys. Status Solidi. 41(2), 659 (1970). https://doi. org/10.1002/pssb.19700410221

63. Q. Ding, Y. Zhang, X. Chen, X. Fu, D. Chen, S. Chen, L. Gu, F. Wei, H. Bei, Y. Gao, M. Wen, J. Li, Z. Zhang, T. Zhum R. O. Ritchie, Q. Yu, Nature 574, 223(2019) https://doi.org/10.1038/ s41586-019-1617-1

64. X. Huang, L. Liu, X. Duan, W. Liao, J. Huang, H. Sun, C. Yu, Mater. Des. 202, 109560 (2021). https://doi.org/10.1016/j.matdes. 2021.109560

65. G. Laplanche, A. Kostka, O.M. Horst, G. Eggeler, E.P. George, Acta Mater. 118, 152 (2016). https://doi.org/10.1016/j.actamat. 2016.07.038
66. S.-H. Joo, H. Kato, M.J. Jang, J. Moon, C.W. Tsai, J.W. Yeh, H.S. Kim, Mater. Sci. Eng. A. 689, 122 (2017). https://doi.org/10. 1016/j.msea.2017.02.043

67. H. Chang, T.W. Zhang, S.G. Ma, D. Zhao, R.L. Xiong, T. Wang, Z.Q. Li, Z.H. Wang, Mater. Des. 197, 109202 (2021). https://doi. org/10.1016/j.matdes.2020.109202

68. X. Tian, Y. Zhang, Mater. Sci. Eng. A. 516(1-2), 73 (2009). https://doi.org/10.1016/j.msea.2009.02.031

69. C.L. Yang, Z.J. Zhang, T. Cai, P. Zhang, Z.F. Zhang, Sci. Rep. 5, 15532 (2015). https://doi.org/10.1038/srep15532 